\title{
Function of a Mulching Sheet for Reforestation and the Prevention of Soil Erosion
}

\author{
Takuya Marumoto*,Seiji Hayakawa*,Tsugio Ezaki**, \\ Kazuo Yamamoto***and Hiroaki Okabe**** \\ ( * Yamaguchi University, Yamaguchi 753, Japan) \\ ( ** Ehime University, Ehime 790, Japan) \\ (*** Central Service Co., Yamaguchi 755, Japan) \\ (****Forestry \& Forest Products Research Institute, Ibaraki 305, Japan)
}

\begin{abstract}
From the experiments at model and actual slopes, several effective functions of a mulching sheet (MS) were indicated on soil erosion and reforestation as follows : 1) drainage of flow water, 2) reduction of muddy water, 3) prevention of soil erosion, 4) decrease of drought damage to soil, 5) decrease of the fluctuation of temperature and moisture in surface soil, 6) reduction of wintry withering, 7) promotion of plant growth, 8) environmental conservation of root zone, 9) environmental improvement of soil microorganisms.
\end{abstract}

Key words: nonwoven fabric sheet, soil erosion, reforestation

\section{Introduction}

A mulching sheet ( MS:nonwoven fabric sheet) with a three layer structure was developed by Marumoto et al. ${ }^{11}$ in 1990 to prevent soil erosion and promote reforestation on bare slopes. The MS is constituted basically of a polyester random fiber ( hollow) web, mineral medium, slow releasing fertilizer, seeds, PVA film and a rayon sheet. From the several experiments at model and actual slopes, some effective functions of MS were observed on soil erosion and reforestation.

\section{Drainage of surface flow water and reduction of muddy water}

Table 1 and 2 indicated the effect of the mulching sheet (MS) on the erosion of Masa soil and the comparison of water flow rate between bare and sheet covered land (slopes). Model slope (W $95 \mathrm{~cm}$ X L $180 \mathrm{~cm}$, slope $10^{\circ}$ ) with Masa soil (depth $5 \mathrm{~cm}$ ) was used in the flow water experiment (Table 1 and 2). In order to prevent to slide Masa soil, the floor of slope was filled by geogrid material. Down edge of slope was divided
Table 1. Effect of the mulching sheet

\begin{tabular}{ccc} 
& \multicolumn{2}{c}{ on the erosion of Masa soil } \\
\hline Time & \multicolumn{2}{c}{ Soil eroded $($ g/min. $)$} \\
\cline { 2 - 3 } (min.) & Bare & Covered \\
\hline 10 & 514.0 & 0.0 \\
20 & 1097.0 & 0.0 \\
30 & 1399.0 & 0.0 \\
40 & 1165.0 & 0.0 \\
50 & 131.4 & 0.0 \\
60 & 202.6 & 0.0 \\
70 & 551.0 & 0.0 \\
80 & 256.0 & 0.0 \\
90 & 224.0 & 0.0 \\
100 & 86.4 & 0.0 \\
110 & 117.4 & 0.0 \\
120 & 103.2 & 0.0 \\
\hline
\end{tabular}

(thickness of sheet : $5 \mathrm{~mm}$, water flow : $70 \mathrm{ml} / \mathrm{s}$, slope : $10^{\circ}$ ) 
by wire net. Surface of the slope was covered by MS. Water $(70 \mathrm{ml} / \mathrm{sec}$.) was flown from top of the slope. Suspended road (eroded soil g/min:Table 1) and flow rate $(\mathrm{cm} / \mathrm{sec} .:$ Table 2$)$ were measured. The erosion of Masa soil was not observed at the mulching slope and flow rates of surface water with experimental time were almost constant and lower than those at the bare slope.

Flow of coloring matter with surface water flow in MS and soil under water saturated conditions was observed in the model experiment using coloring matter addition (Fig.1). The same model slope as former experiment was used in this experiment. Coloring matters (blue) were added at A: surface of the MS, B:in the sheet, C:the border between the sheet and soil, D:in soil $(1.5 \mathrm{~cm}$ depth) in Fig.1, respectively. The coloring matter tends to flow down in the MS more than in soil. The MS could constantly drain the surface flow water and therefore reduce muddy water ( Photo 1).
Table 2. Comparision of the water flow rate between bare and sheet- covered land

\begin{tabular}{rrr}
\hline \multirow{2}{*}{$\begin{array}{c}\text { Time } \\
\text { (min.) }\end{array}$} & \multicolumn{2}{c}{ Flow rate $(\mathrm{cm} / \mathrm{s})$} \\
\cline { 2 - 3 } & Bare & Covered \\
\hline 5 & 8.64 & 4.28 \\
45 & 11.46 & 4.03 \\
105 & 13.64 & 3.96 \\
125 & 15.00 & 4.48 \\
\hline
\end{tabular}

(flow water : $70 \mathrm{mV} / \mathrm{s}$ )

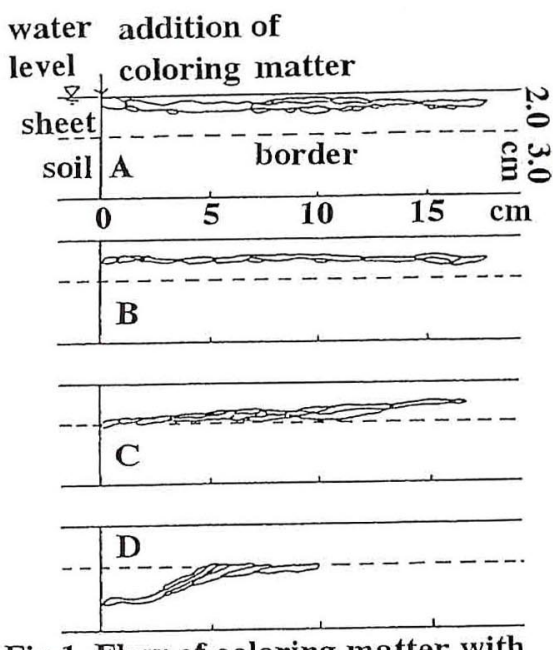

Fig.1. Flow of coloring matter with surface water flow in the sheet and soil under water saturated conditions. (water level : $5 \mathrm{~cm}$, flow water : $60-80 \mathrm{~cm} / \mathrm{s}$, slope : $14.5^{\circ}$ )

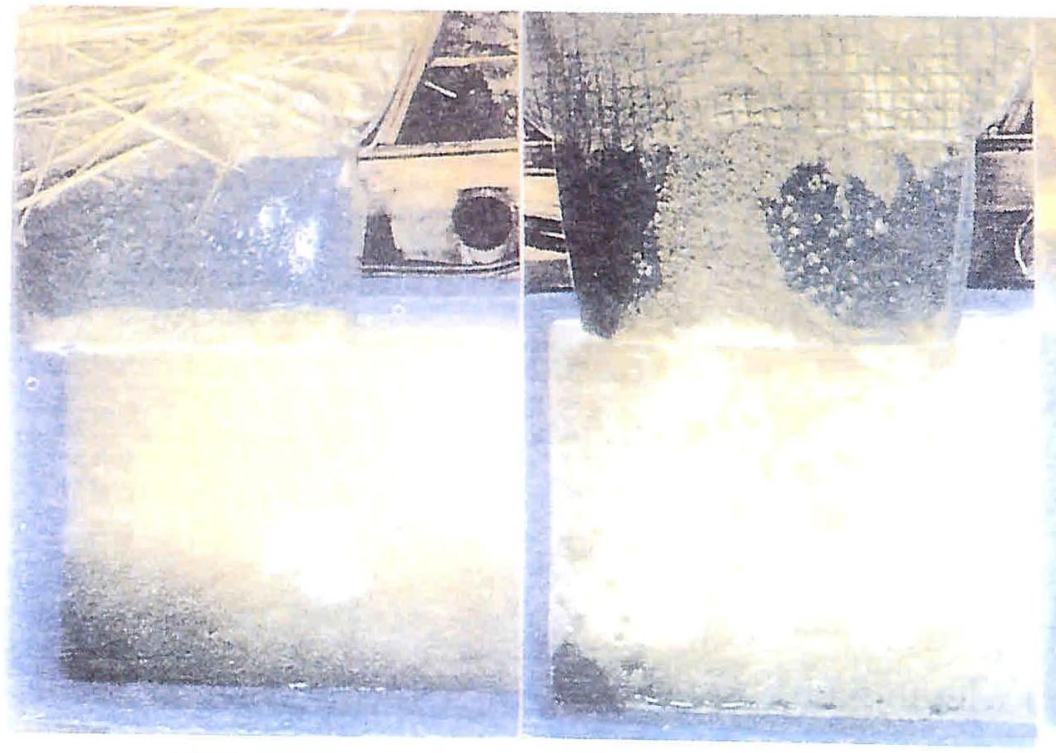

(a) Straw mat (i) Other sheet

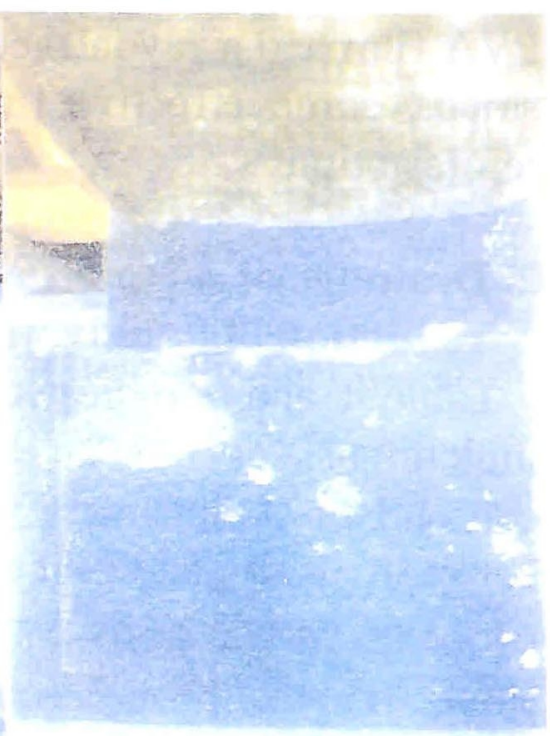

(c) $\mathrm{MS}$

Photo 1. Condition of flow water in model rainfall experiment at National Research Center for Disaster Prevention, Tsukuba, 1991. (rainfall: $50 \mathrm{~mm} / \mathrm{h}$, slope: $20^{\circ}$, flame: $1 \mathrm{~m}$ (W) $X$ $10 \mathrm{~m}(\mathrm{~L})$, Photograph of suspended road in sedimentation box at the end of slope after thr rainfall.) 


\section{Environmental conservation and improvement of root zone}

The basic structure of the MS is shown in Fig.2. Changes in surface temperature and moisture of the soils covered with the MS and noncovered (bare) were measured automatically during several months at an actual mountain slope. A model of the changes in surface temperature and moisture of soil is indicated in Fig.3. The fluctuation of temperature and moisture in the surface soil covered with the MS decreased clearly. Therefore, the environmental condition of the root zone was improved considerably and the growth of pine trees was promoted significantly (Photo 2). Furthermore, the drought damage and wintry withering of plants and trees were also reduced ${ }^{2}$ (Photo 3 ).

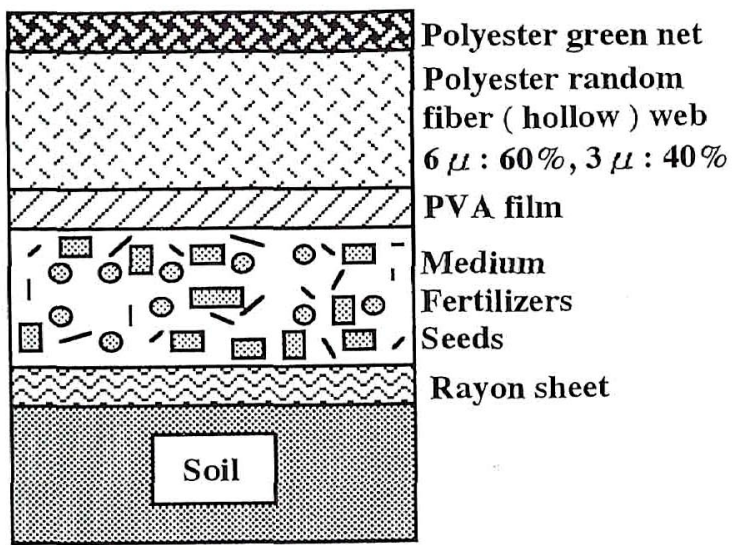

Fig.2. Structure of the mulching sheet
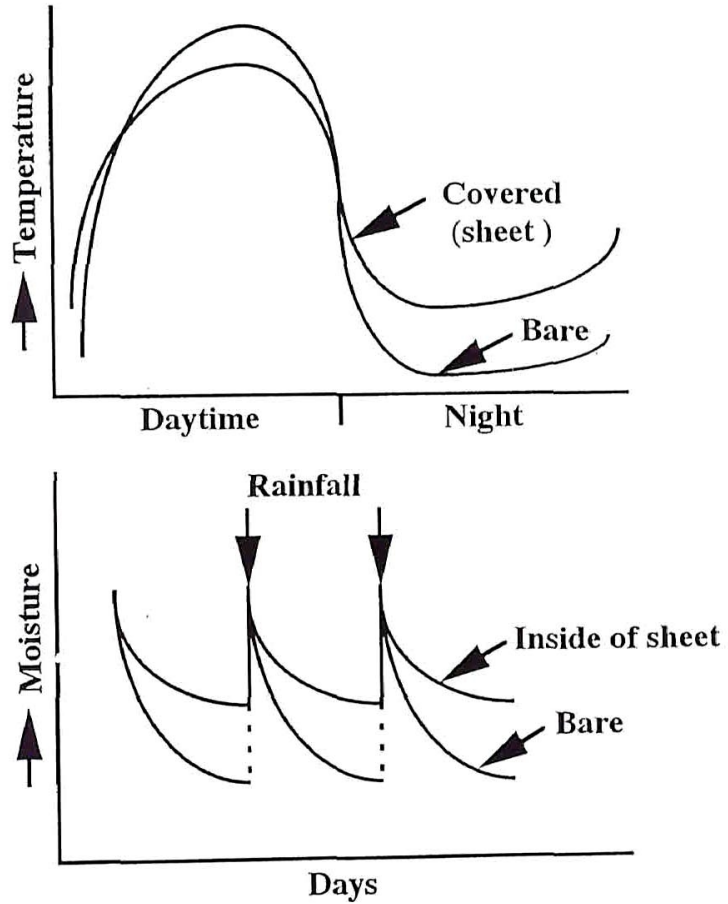

Fig. 3. Model of changes in surface temperature and moisture of soil covered with the sheet

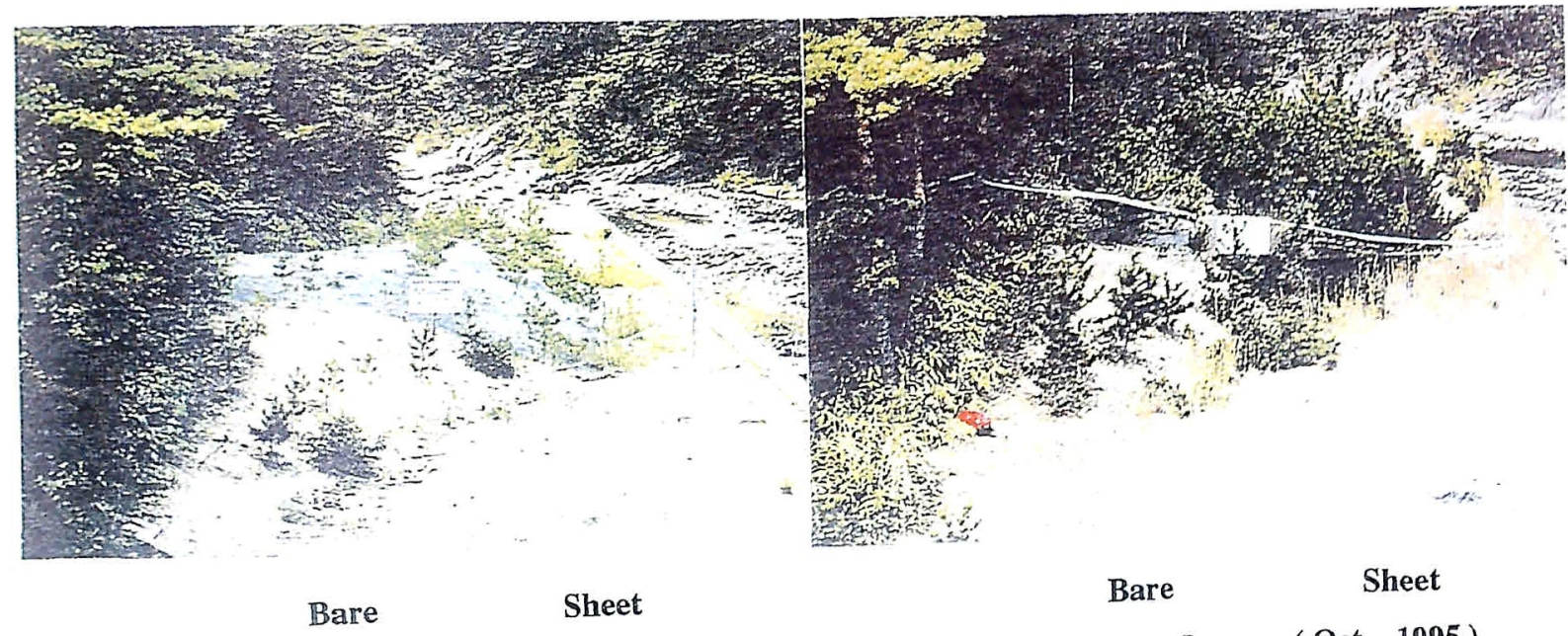

(a) After 4 months (July, 1992) (b) After 3.5 years (Oct., 1995 )

Photo 2. Effect of the mulching sheet on the growth of pine trees 


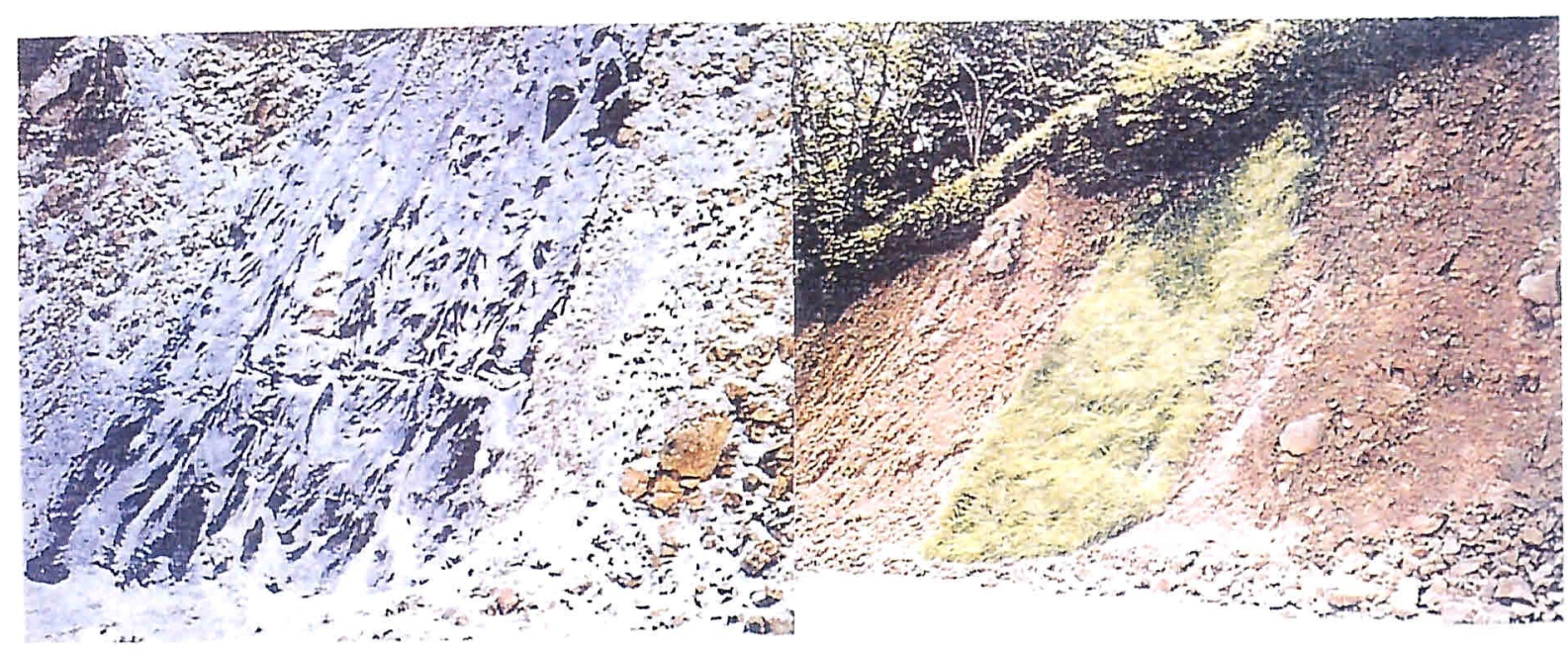

(a) Winter (Jan., 1990)

(b) Spring (May, 1991)

Photo 3. Prevention effect on soil erosion in winter at Kano, Yamaguchi ( $700 \mathrm{~m}$ above sea level ), 1990-1991

\section{Conclusion}

From these findings, the multiple functions of this nonwoven sheet (MS) on soil conservation, improvement of root environment for plants and trees, promotion of initial plant growth and reforestation were confirmed.

\section{References}

1) Marumoto,T., Fujiwara,T., Tsunemura,T., Tsunemori,I., Yamamoto K. and Onaga,K., 1990:Development of a mulching sheet on soil conservation and reforestation. Proc. Symp. National Disaster \& Earth Environment, Yamaguchi, 16-24.

2) Marumoto,T., Hayakawa,S., Ezaki,T., Yamamoto K. and Okabe H., 1993: Effect of cover sheet on soil erosion and following planting and its application examples. Proc. Symp. Applications of Mulching Materials for Soil and Water Conservation, Taiwan, 49-62 . 